\title{
PROSTHESIS FOR OPEN PLEUROSTOMY VERSUS OPEN THORACIC WINDOW
}

doi: 10.1590/S1807-59322009000600017

Artur Eugênio de Azevedo-Pereira

Dear editor,

We read with great interest the article by Filomeno et al. ${ }^{1}$ They reported the follow-up of 44 patients with chronic pleural empyema treated with an ingenious prosthesis for open pleurostomy (POP), as an alternative to open thoracic window (OTW). However, some aspects need to be considered. First, the early closure of the stoma created at an OTW seems to be more related to individual technical problems, like a too small stoma, than a disadvantage of the procedure itself. Commonly, the spontaneous closure of the stoma occurs in concomitance with pleural infection resolution. ${ }^{2}$ Second, for critically ill or debilitated patients who cannot tolerate the OTW, chest tube drainage, a simpler and widely used procedure, seems to be a more useful alternative.

We agree that the POP could be part of the general thoracic surgeon's armamentarium. However, clinical trials comparing OTW and POP are needed to establish objective indication criteria for this new operative device, in order to improve the care of patients with chronic pleural empyema.

\section{REFERENCES}

1. Filomeno LTB, Campos JRM, Machuca TN, Neves-Pereira JC, Terra RM. Prosthesis for open pleurostomy (POP): management for chronic empyemas. Clinics. 2009;64:203-8.

2. Deslauriers J, Jacques LF, Grégoire J. Role of Eloesser flap and thoracoplasty in the third millennium. Chest Surg Clin N Am. 2002;12:605-23. 